\title{
Simulasi Sistem Monitoring Arus Lebih Pada Jaringan PLN Satu Fasa Menggunakan Web Berbasis Mikrokontroller
}

\author{
Yul Antonisfia ${ }^{1}$, Muhammad Irmansyah ${ }^{2}$, Anggara Nasution ${ }^{3}$ \\ ${ }^{123}$ Jurusan Teknik Elektro Politeknik Negeri Padang \\ mirmansyah38@gmail.com \\ Kampus Politeknik Negeri Padang, Limau Manis Padang
}

\begin{abstract}
Modernization is indeed very influential in the lives of people today, with the existence of this modern era, everything is always related to technology. The place is far enough and to find out the condition of the excess current makes the PLN officials also have difficulty because there is no monitoring tool from the situation. From the description above, the author found the idea to make a Simulation System for Monitoring Overcurrent Systems in the PLN Phase One Phase Using a Microcontroller-Based Web. The tool uses the Arduino Mega microcontroller coupled with ACS712 Flow sensors, and Ethernet Shield Modules. The way this tool works is to detect the electric current that enters the Input from the electrical equipment load on the ACS712 sensor. In testing the author only uses 3 pieces of light as a burden to determine the state of excess current. If you use 1 load, the current that is read is $0.44 \mathrm{~A}$ with a 100 Watt lamp power. And if the load is added by 1 load with 75 Watt of light power, the current that is read becomes 0.77A. Then the load is added with 1 lamp with a power of 60 Watt, then the current becomes 1.05A with the result at all three drop loads.
\end{abstract}

Keywords: current monitoring, WEB, ACS712, microcontroller, ethernet shield.

\begin{abstract}
Abstrak-Modernisasi memang sangat berpengaruh besar dalam kehidupan masyarakat sekarang, dengan adanya era modern ini semuanya selalu berhubungan dengan teknologi. Tempat yang cukup jauh serta untuk mengetahui keadaan arus berlebih membuat para petugas PLN pun kesulitan dikarenakan belum terdapat alat monitoring dari keadaan tersebut. Dari gambaran diatas, penulis menemukan ide untuk membuat alat Simulasi Sistem Monitoring Arus Lebih pada Jaringan PLN Satu Fasa Menggunakan Web Berbasis Mikrokontroler. Alat tersebut menggunakan microcontroler Arduino Mega ditambah dengan sensor Arus ACS712, dan Modul Ethernet Shield. Cara kerja alat ini adalah mendeteksi arus listrik yang masuk pada Input dari beban peralatan listrik pada sensor ACS712. Pada pengujian penulis hanya menggunkan 3 buah lampu sebagai beban utntuk mengetahui keadaan arus berlebih. Jika menggunakan1 buah beban, arus yang terbaca sebesar 0,44A dengan daya lampu 100 Watt. Dan jika beban ditambah 1buah beban dengan daya lampu 75 Watt, arus yang terbaca menjadi $0,77 \mathrm{~A}$. Lalu beban ditambah dengan 1 buah lampu dengan daya 60 Watt, maka arus menjadi 1,05A dengan hasil pada ketiga beban drop.
\end{abstract}

Kata kunci: monitoring arus, WEB, ACS712, mikrokontroler, ethernet shield

(C) 2018 Elektron Jurnal Ilmiah

\section{Pendahuluan}

Tenaga listrik merupakan sumber energi yang sangat penting bagi kehidupan manusia baik untuk kegiatan industri, kegiatan komersial maupun dalam kehidupan sehari-hari rumah tangga. Energi listrik dibutuhkan untuk memenuhi kebutuhan penerangan dan juga proses produksi yang melibatkan barangbarang elektronik dan alat-alat industri. Mengingat begitu besar dan pentingnya manfaat energi listrik sedangkan sumber energi pembangkit listrik terutama yang berasal dari sumber daya tak terbarui keberadaannya terbatas, maka untuk menjaga kelestarian sumber energi ini perlu diupayakan langkah-langkah strategis yang dapat menunjang penyediaan energi listrik secara optimal dan terjangkau.

Gardu distribusi merupakan salah satu Komponen dari suatu sistem distribusi PLN yang berfungsi untuk menghubungkan jaringan ke konsumen atau untuk mendistribusikan tenaga listrik pada konsumen atau pelanggan, baik itu pelanggan tegangan menengah maupun pelanggan tegangan rendah. Gardu Distribusi tegangan Listrik yang Paling di kenal adalah sebuah bangunan Gardu Listrik yang berisi atau terdiri dari instalasi Perlengkapan Hubung Bagi Tegangan Menengah (PHB-TM), Transformator Distribusi, dan Perlengkapan Hubung Bagi Tegangan Rendah (PHBTR), untuk memasok kebutuhan tenaga listrik bagi para pelanggan, baik dengan tegangan menengah (TM 20 KV ) maupun Tegangan rendah (TR 220/380 Volt). Dalam Gardu Distribusi ini Biasanya digunakan Transformator distribusi yang berfungsi untuk menurunkan tegangan listrik dari jaringan distribusi tegangan tinggi menjadi tegangan terpakai pada jaringan distribusi tegangan rendah (step down transformator); misalkan tegangan 20 
KV menjadi tegangan 380 volt atau 220 volt. Sedang transformator yang digunakan untuk menaikan tegangan listrik (step up transformator), hanya digunakan pada pusat pembangkit tenaga listrik agar tegangan yang didistribusikan pada suatu jaringan panjang dan tidak mengalami penurunan tegangan.Pada penelitian ini penulis mengambil referensi dari beberapa sumber yang memiliki keterkaitan alatnya dengan alat yang penulis buat.

Pertama dari penelitian Rezky Setiawan [1] yang berjudul sistem monitoring putusnya $\mathrm{NH}$ fuse pada gardu ditribusi PLN, fungsi alat ini adalah monitoring putusnya $\mathrm{NH}$ fuse karena dropnya tegangandan mengkur arus yang keluar sedangkan yang kedua dari Azka Purba Anggiawan [2] yang berjudul perancaan alat monitoring penggunaan daya listrik secara detail menggunakan mikrokontroler, prinsip kerja alat ini adalah mendeteksi arus listrik yang masuk Input dari beban peralatan listrikpada sensor ACS712, maka secara sistem sensor akan menerima arus masuk tersebut kemudian arus tersebut di arahkan pada modul microcontroler Arduino Uno untuk mengkonversikan secara sistem dengan hitungan rumus daya $(\mathrm{Wh}) \mathrm{Wh}=\mathrm{Ixt}$ (Arus $\mathrm{x}$ waktu) sehingga akan mendapatkan hasil daya listrik yang di pakai selama pemakaian dalam bentuk laporan $C S V$.

Yang ketiga penelitian Adrizal [3] yang berjudul Rancang bangun siste proteksi generator dari arus beban lebih dan drop berbasiskan mikrokontroler arduino. Tujuan dari pembuatan alat tersebut adalah untuk memperoleh peralatan yang dapat memproteksi genarator listrik dari arus beban berlebih dan drop tegangan yang terjadi secara digital. Disini penulis mengembangkan sebuah alat yang telah ada. Pada penelitian ini membuat "suatu sistem monitoring kerusakan padajaringan gardu distribusi Satu Fasa menggunakan web berbasis mikrokontroler menggunakan sensor arus ACS712, agar petugas PLN dapat bekerja dengan optimal apabila terjadi gangguan pada gardu distribusi. Dan untuk mengetahui arus beban yang berlebih.

\section{METODE PENELITIAN}

Dalam perancangan sebuah alat, hal pertama yang harus dilakukan yaitu proses perancangan. Tujuan dari perancangan ini adalah untuk mempermudah dalam pembuatan alat, karena pada perancangan akan dilakukan pembuatan rangkaian serta pemilihan komponen yang tepat.Adapun dalam perancangan sistem adalah membuat suatu blok diagram sebagai acuan, dimana setiap blok mempunyai fungsi tertentu dan saling terkait sehingga membentuk sistem dari alat yang di buat kemudian dilakukan perancangan perangkat keras (hardware) dan perancangan perangkat lunak (software).

\section{A. Blok Diagram}

Perancangan alat dibuat untuk membantu dan mempermudah dalam mengerjakan alat yang akan dibuat. Perancangan alat dimulai dari pembuatan blok diagram dimana setiap blok tersebut mempunyai fungsi tersendiri yang saling terkait sehingga membentuk sistem dari alat yang akan dibuat. Berikut blok diagram system pada gambar 1 .

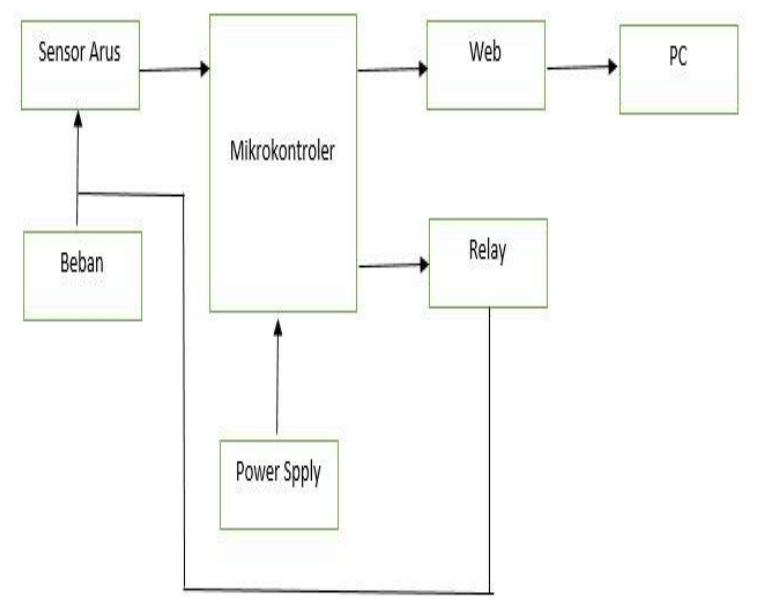

Gambar 1. Blok Diagram Rancangan Sistem

Alat yang dibuat memiliki prinsip kerja untuk menampilkan nilai pembacaan sensor arus pada jalajala PLN yang ditampilkan pada WEB, sehingga membuat engineer PLN dapat memantau arus yang mengalir pada jala-jala PLN tanpa harus melakukan penegecekkan secara langsung. Untuk pengoperasiannya alat ini dikontrol menggunakan mikrokontroler arduino, dimana data pembacaan sensor arus ACS712 akan diproses oleh mikrokontroler dan kemuadian dikirim ke alamat WEB yang telah diatur pada program arduino. Monitoring pada WEB menampilkan data berupa grafik pemakaian arus. Pada saat arus yang terbaca oleh sensor ACS 712 memiliki nilai diatas 0.85 A maka beban akan drop-out (mati).

\section{B. Perancangan dan Pembuatan Hardware}

Perancangan dan pembuatan hardware Sistem monitoring Arus lebih pada jaringan PLN satu fasa berbasis web menggunakan sensor arus ACS712, terdiri dari perancangan mekanik dan perancangan elektronik. Perancangan mekanik yaitu membuat perancangan untuk mekanik pintu dan perancangan elektronik yaitu membuat rangkaian elektronika yang akan direalisasikan ke bentuk PCB (Printed Circuit Board). 


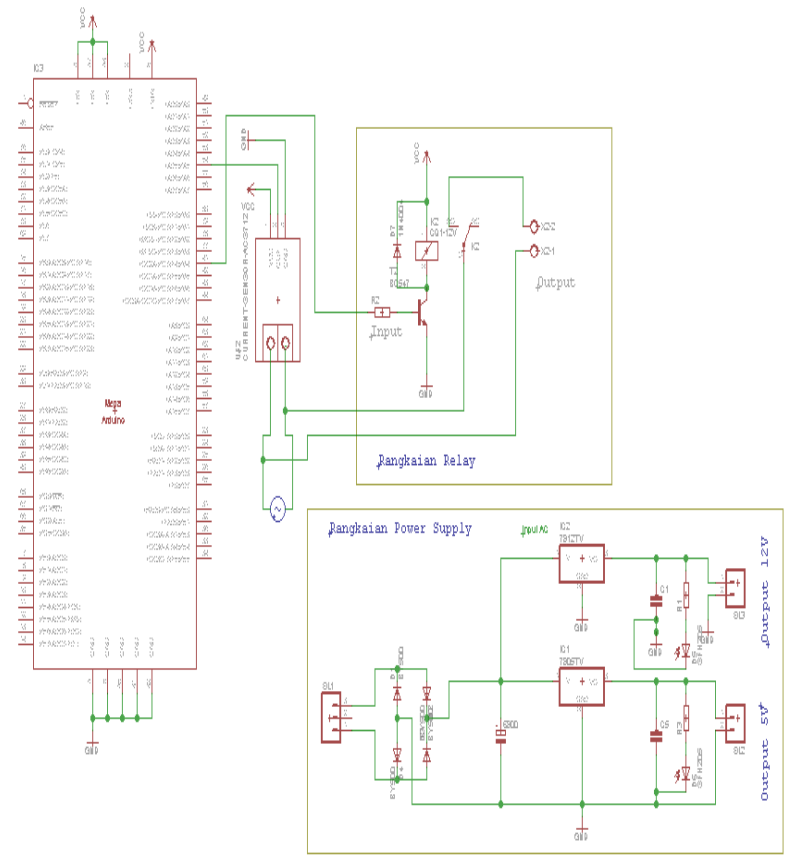

Gambar 2. Rangkaian Simulasi Sistem Monitoring Arus Lebih Pada jaringan PLN Satu Fasa Menggunakan Web

Rangkaian power supply berfungsi sebagai sumber tegangan utama dari alat yang akan dibuat. Rangkaian power supply memanfaatkan tegangan dari PLN sebesar 220 VAC. Tegangan dari PLN ini terlalu besar, sehingga digunakan trafo step down 3 ampere dengan keluaran tegangannya dibuat 12 VAC. Output ini telah sesuai dengan menggunakan IC 7805. Selanjutnya tegangan akan disearahkan oleh dioda sehingga tegangan AC dirubah menjadi tegangan DC. Kapasitor untuk filter sehingga bentuk gelombang tegangan keluarnya bisa menjadi rata.Sensor arus satu fasa berfungsi untuk mendeteksi kondisi tegangan. Sensor arus satu fasa tersebut terhubung di pin A5 pada mikrokontroler. Relay adalah saklar elektrik yang aktif apabila diberikan tegangan, pada alat ini relay difungsikan untuk mengaktifkan dan mematikan beban. Apabila sensor ACS712 mendeteksi arus yang mengalir pada beban adalah besar dari $0.85 \mathrm{~A}$. Maka beban akan mengalami trip.

\section{Perancangan Mekanik}

Perancangan mekanik bertujuan untuk merencanakan sesuatu yang akan dibuat dalam bentuk mekanik. Hasil perancangan mekanik dari tugas akhir ini dapat dilihat pada gambar 3. Spesifikasi dari alat yang dibuat ini adalah :

- Dimensi Alat 26x17x10 cm.

- Menggunakan SensorArus ACS 712..

- Menggunakan Mikrokontroller Arduino Mega 2560.

- Menggunakan Arduino ethernet shield pada mikrokontroller.

- Menggunakan relay 5V DC
- Menggunakan bola lampu (lampu pijar/beban)

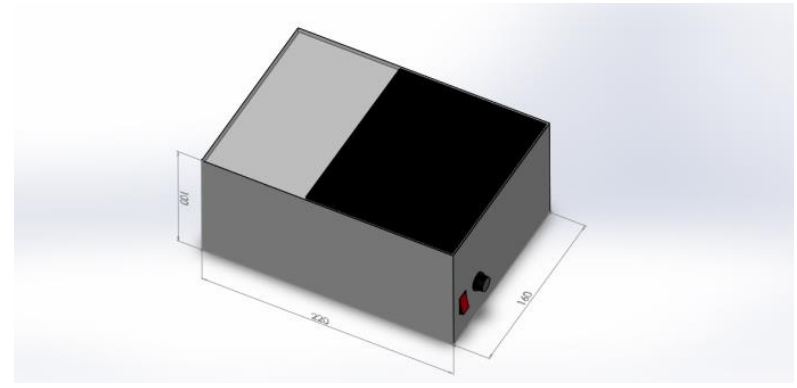

Gambar 3. Rancangan Mekanik Tampak Isometric

\section{Perancangan Perangkat Lunak (Software)}

Langkah pertama dalam perancangan ini adalah membuat algoritma. Algoritma merupakan garis besar jalannya suatu program, salah satu algoritma dituangkan dalam bentuk flow chart (diagram alir). Terlihat pada gambar 4 merupakan flow chart yang akan menjelaskan arah suatu program.

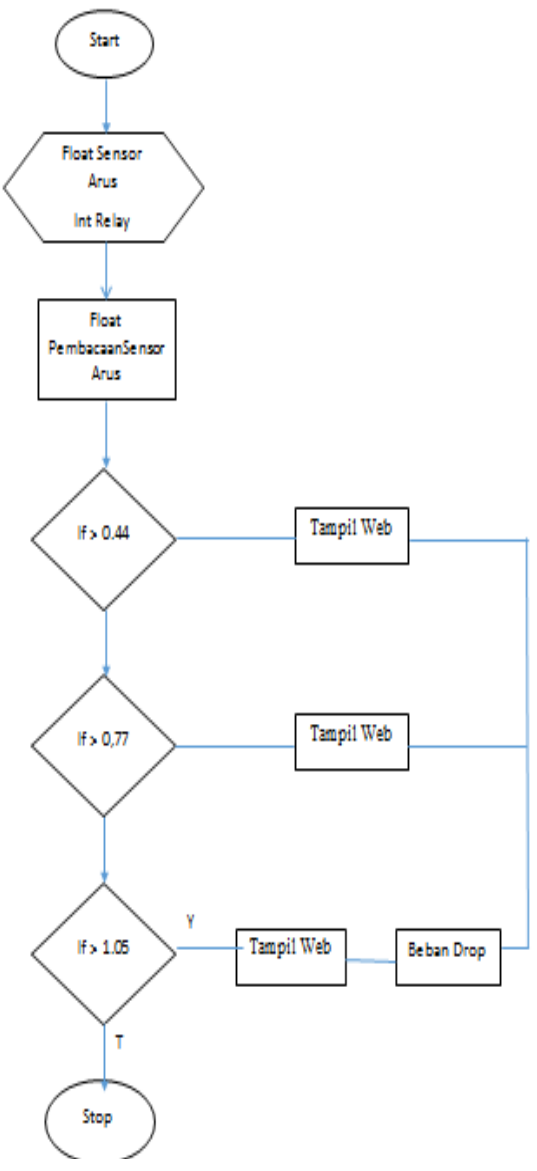

Gambar 4. Flowchart 
Dari flowchart diatas deskripsi dari alat " Simulasi Sistem Monitoring Arus Pada jaringan PLN Satu Fasa Berbasis Web", dapat dijelaskan sebagai berikut : Sistem akan memintoring arus pada jaring PLN, arus akan terbaca oleh sensor ACS712 yang akan dikirimkan melalui internet dan dapat langsung dilihat melalui web, jika arus yang terbaca melebihi batas atau beban telah melebihi maka secara otomatis akan terjadi trip pada sistem, dan jika arus telah stabil kembali secara otomatis sistem akan hidup dan pembacaan beban akan kembali normal.

\section{E. Perancangan Web Interface}

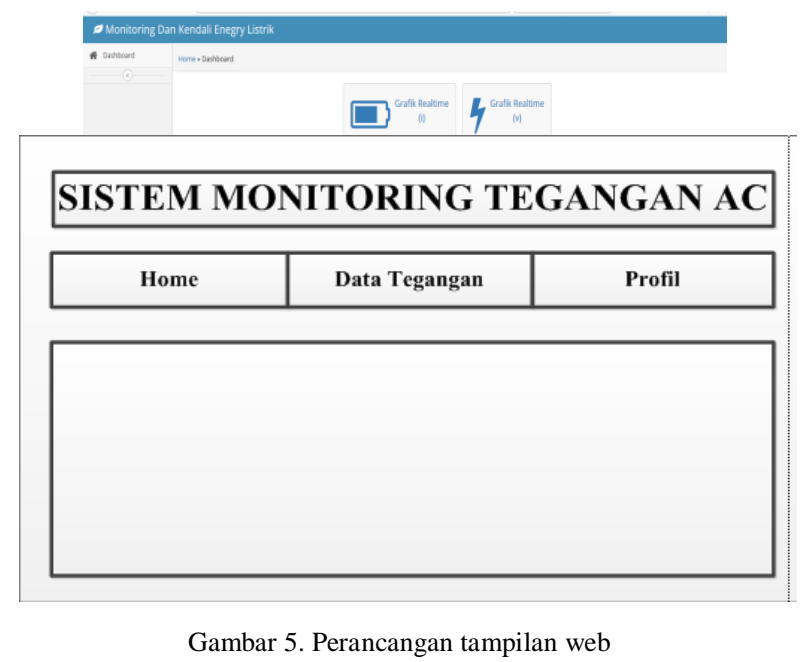

Pada gambar 5 merupakan tampilan jendela web. Pada menu Grafik Realtime (I) digunakan untuk mikrokontroller, kemudian hasil yang siap diolah tersebut ditampilkan pada WEB. Tampilan pada WEB tersebut berupa grafik dari data arus yang terbaca oleh sensor arus ACS712 dan pada tampilan web ini terdapat indikator berupa LED, apabila tegangan trip maka LED akan mati dan jika tegangan normal maka LED akan hidup/menyala.

\section{HASIL DAN PEMBAHASAN}

Pengujian merupakan salah satu langkah penting yang harus dilakukan untuk mengetahui apakah sistem yang dibuat telah sesuai dengan yang direncanakan, hal itu dapat dilihat dari hasil yang diperoleh dalam pengujian sistem.Berikut langkah-langkah dan pokok pembahasan yang akan di lakukan dalam pangujian sebagai berikut :

A. Pengujian sensor arus ACS712

B. Pengujian Relay

\section{A. Pengujian Sensor ACS712}

Sensor arus ACS712 ini digunakan untuk mengukur arus beban. Pengujian pada rangkaian sensor arus dilakukan dengan menggunakan tegangan sumber 220 Volt AC. Pemasangan sensor arus ACS712 ini dilakukan secara seri. Untuk batas maksimal pembacaaan arus dengan menggunakan sensor ini adalah sebesar 30 A. Sebelum sensor arus ini digunakan dalam sistem, terlebih dahulu dilakukan pengujian sensor dengan membandingkan nilai pembacaan sensor dengan ampermeter. Untuk pengujian sensor arus ini digunakan lampu pijar sebagai beban. Beban lampu pijar ini pun di bedakan, sehingga untuk setiap pengujian tidak menggunakan besar beban yang sama. Untuk tegangan yang digunakan sebesar 220 Volt. Hal ini dilakukan agar diketahui sensitifitas dari sensor tersebut. Kemudian pembacaan sensor tersebut akan dibandingkan dengan pengukuran yang dilakukan dengan ampermeter. Hasil pengujian dapat dilihat pada tabel 1 dan tabel 2.

\begin{tabular}{|c|c|c|c|}
\hline No & Beban & $\begin{array}{cc}\text { Arus } & \text { Pe } \\
\text { Terbaca } & \text { M }\end{array}$ & $\begin{array}{l}\text { Pengukuran } \\
\text { Multimeter }\end{array}$ \\
\hline $\begin{array}{l}\text { Beban } 1 \\
\text { Beban } 2 \\
\text { Beban } 3\end{array}$ & $\begin{array}{c}100 \\
\text { Watt } \\
75 \\
\text { Watt } \\
60 \\
\text { Watt }\end{array}$ & $\begin{array}{l}0.41 \mathrm{~A} \\
0.32 \mathrm{~A} \\
0.28 \mathrm{~A}\end{array}$ & $\begin{array}{l}0.43 \mathrm{~A} \\
0.34 \mathrm{~A} \\
0.26 \mathrm{~A}\end{array}$ \\
\hline Jumlah & $\begin{array}{c}235 \\
\text { Watt }\end{array}$ & $1.01 \mathrm{~A}$ & $1.03 \mathrm{~A}$ \\
\hline \multicolumn{4}{|c|}{ Tabel 2. Pengujian Sistem } \\
\hline No & Beban & $\begin{array}{c}\text { Keadaan } \\
\text { Arus }\end{array}$ & $\begin{array}{c}\text { Arus } \\
\text { Terbaca }\end{array}$ \\
\hline 1 & Tanpa Beban & Mengalir & $0.00 \mathrm{~A}$ \\
\hline 2 & Beban 1 & Mengalir & $0.41 \mathrm{~A}$ \\
\hline 3 & $\begin{array}{c}\text { Beban } 1+ \\
\text { Beban } 2 \\
\end{array}$ & Mengalir & $0.73 \mathrm{~A}$ \\
\hline 4 & $\begin{array}{c}\text { Beban } 1+ \\
\text { Beban } 2+ \\
\text { Beban } 3\end{array}$ & Drop Out & $1.01 \mathrm{~A}$ \\
\hline
\end{tabular}

Untuk dapat mengetahui keakuratan sensor terhadap nilai daya maka dapat dihitung melalui persamaan berikut.

$$
\begin{gathered}
P=V x I \\
I=\frac{P}{V}
\end{gathered}
$$

Dari hasil pengukuran dari analisa menggunakan persamaan diatas terlihat bahwa nilai yang terbaca oleh sensor memiliki error yang dikatakan wajar dan bisa dikatakan pembacaannya hampir sempurna.Prinsip dari kerja alat yang telah diuji dilakukan dengan menggunakan beban yang berbedabeda. Beban yang digunakan yaitu 100 Watt, 75 Watt dan 60 Watt. Langkah pertama beban yang digunakan sebesar 100 Watt arus yang terbaca sebesar 0.44A. langkah yang kedua dimasukan beban sebesar 75 Watt arus yang terbaca sebesar 0.77A. Dan apabila dipakai beban yang ketiga beban akan trip, karena beban yang digunakan terlalu besar. Sebab apabila beban yang digunakan besar dari $0.85 \mathrm{~A}$ beban akan trip. 


\section{B. Pengujian Relay}

Relay digunakan sebagai penghubung dan pemutus arus, dimana tegangan digunakan untuk beban 220 VAC dengan input relay agar aktif yakni 5 VDC. Pada relay terdapat kontak NO dan NC. Pada kontak tersebut akan apabila diberi logika LOW maka relay dari NO menjadi NC begitu sebaliknya. Hal itu dikarenakan relay yang digunakan adalah aktif LOW. Pengujian relay dapat dilakukan dengan mengukur tegangan input yang masuk pada relay dan kontak output pada relay (NO/NC) dengan bantuan multimeter yang akan memberikan respon terhadap aktif atau tidaknya relay pada bagian output (beban). Hasil pengujian dapat dilihat pada tabel 3. Tabel 3 Hasil Pengujian Relay

\begin{tabular}{cccc}
\hline Logika & Tegangan & Arus & $\begin{array}{c}\text { Keadaan } \\
\text { Relay }\end{array}$ \\
\hline LOW & $5 \mathrm{VDC}$ & $10 \mathrm{~A}$ & Aktif \\
\hline HIGH & 0 VDC & 0 A & Mati \\
\hline
\end{tabular}

Adapun relay yang digunakan adalah modul relay dengan keadaan aktif LOW. Dimana berdasarkan hasil pengujian apabila mikrokontroler arduino memberikan logika LOW maka relay akan aktif dan memberikan tegangan 5 VDC sesuai dengan pin digital arduino yang digunakan dan sebaliknya apabila mikrokontroler arduino memberikan logika HIGH maka relay akan mati dengan tegangan keluaran pada arduino yakni 0 VDC. Jadi penggunaan modul relay ini dengan mikrokontroler melalui pin digital.Pada alat ini relay bekerja untuk memutus beban ketika sensor ACS712 menedeteksi arus yang melewati beban memiliki nilai lebih dari 0,85 Ampere.

\section{Pengujian Sistim Keseluruhan}

Pengujian secara keseluruhan dilakukan melalui jaringan yang terhubung ke internet lewat kabel LAN, dan data ditampilkan lewat web.Setelah dilakukan pengujian secara keseluruhan didapatkan nilai berupa grafik yang dapat dilihat pada gambar 6 dan 7 .

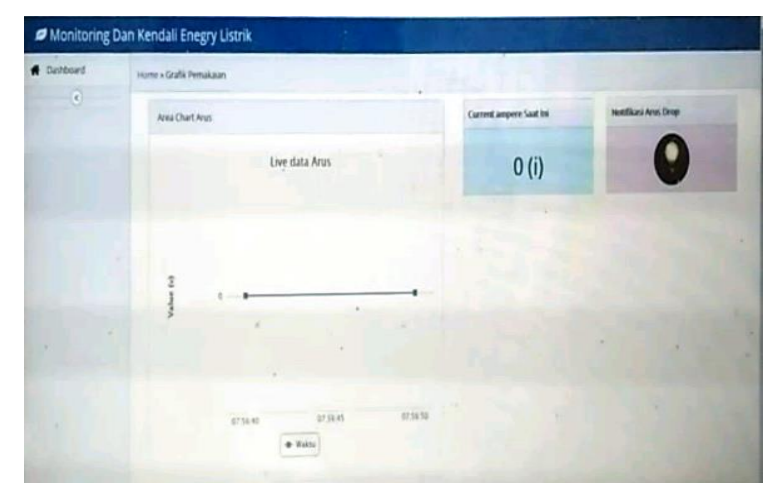

Gambar 6. Tampilan web tanpa beban

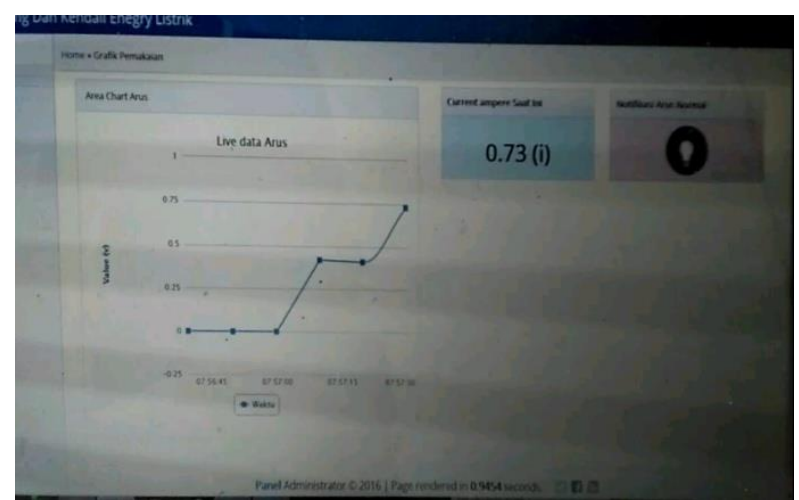

Gambar 7. Tampilan web dengan 2 beban

Dari grafik yang nampak diatas, terlihat jelas perbandingan pengukuran antara sensor arus ACS712 dengan ampermeter, pada kedua pengukuran tersebut terdapat perbedaan nilai. Hal ini disebabkan oleh adanya pengukuran eror-eror pada sensor arus karena disebabkan faktor gangguan luar. Namun dari hasil pengujian diatas, kerja dari sensor arus tersebut bisa dikatakan akurat dengan amperemeter. Untuk mendapatkan data grafik, terlebih dulu mengakses melalui internet.

Dengan memasukan alamat WEB yaitu elektro.polinpdg.ac.id/pemakaian. Pada gambar 6, merupakan bentuk awal dari tampilan web setelah diakses melalui internet. Untuk melihat grafik dan data arus yang terbaca, maka klik gambar grafik realtime akan muncul tampilan seperti pada gambar 6. Dapat dilihat keadaan arus yang terbaca masih normal. Jika beban ditmbahkan seperti Pada gambar 7 dapat dilihat bahwa arus yang terbaca sebesar 0.44 , dan dapat juga dilihat pada grafik. Pada gambar 33 dapat dilihat bahwa arus telah berubah menjadi 0.77 a,dikarenakan telah dipakai 2 beban.

Pada keadaan stabil (normal), dapat dilihat arus dan beban yang ditampilkan, perubahan arus yang tidak stabil dapat dilihat dari grafik yang terbaca oleh sensor yang di monitoring melalui web. Keadaan ini menandakan bahwa beban yang dibaca oleh sistem telah melampaui batas, dan mengakibatakan drop pada sistem dan menyebabkan kedua lampu yang lainnya mati, namun jika keadaan kembali stabil, disini digambarkan dengan arus yang terbaca kembali dan pembacaan yang normal, keadaan ini digambarkan dengan nilai arus yang terbaca kurang dari $1 \mathrm{~A}$, dan 2 lampu lainnya akan kembali hidup.

\section{Kesimpulan}

1 Sensor arus ACS712 yang digunakan untuk mengukur arus beban yang dipakai.Apabila dimasukan 1 beban arus yang terbaca $0.44 \mathrm{~A}$, dan ditambah satu beban lagi arus yang terbaca $0.77 \mathrm{~A}$, ditambah satu beban lagi, arus yang terbaca sebesar 1.05A. 
2 Beban akan trip apabila arus tersebut melebihi batas maksimal 0.85 A yang telah di setting di program.

3 Fungsi Ethernet shiled untuk Arduino adalah untuk membentuk system komunikasi melalui Ethernet untuk menghubungkan Arduino dengan Arduino atau Arduino dengan web server.

4 Pada web dapat dilihat data arus yang terbaca berupa grafik dan data. Disini juga dapat dilihat waktu, ketika beban ditambah maka waktu akan terlihat pada jam berapa beban tersebut ditambah.

\section{REFERENSI}

[1] Kadir, Abdul. 2013. Panduan Praktis Mempelajari Aplikasi Mikrokontroler dan Pemrogramannya menggunakan arduino. Yogyakarta : ANDI

[2] Malvino, Albert P. 1985. Prinsip-prinsip Elektronika Jilid 1. Jakarta :Erlangga
[3] Mochamad Fajar Wicaksono dan Hidayat. 2017. Mudah Belajar Mikrokontroler Arduino. Bandung : Informatika

[4] Fitriandi Afrizal, "Rancang Bangun Alat Monitoring Arus dan Tegangan Berbasis Mikrokontroller dengan SMS Gateway", ELECTRICIAN-Jurnal Rekayasa dan Teknologi Elektro, 2016

[7] Fakarilmi Hadi, "Perancangan dan Implementasi Sistim Kontrol dan Monitoring KWH Meter Digital Mengggunakan SMS Gateway", e-Proceding of Engineering:Vol.2 Agustus 2015/page 2555

[8] Safii Muhammad, "Perancangan Sistim Monitoring Tegangan Output Genset Menggunakan Ethernet Shield \& SMS Gateway Berbasis Arduino Uno", METIK Jurnal Vol.2. No.2 tahun 2018/page 46

[9] Iqbal Gilang, "Sistim Monitoring Proses Charging Lampu Penerangan Jalan Umum Berbasis SMS Gateway", Tugas Akhir, Universitas Jember, 2016

[10] Ketut Resika Arthana, "Perancangan Alat Pendeteksi Detak Jantung Dan Notifikasi Melalui SMS”, Seminar Nasional Riset Inovatif, 2017 